\title{
Comparison of photosynthesis and antioxidant performance of several Citrus and Fortunella species (Rutaceae) under natural chilling stress
}

Jérémie Santini, Jean Giannettini, Olivier Pailly, Stéphane Herbette, Patrick Ollitrault, Liliane Berti, François Luro

J. Santini, O. Pailly, F. Luro

INRA, UR 1103 Génétique et Ecophysiologie de la Qualité des Agrumes, F-20230 San Giuliano, France

J. Santini, J. Giannettini*, L. Berti

CNRS, UMR 6134 SPE, Laboratoire Biochimie \& Biologie Moléculaire du Végétal, F-20250 Corte, France

*Corresponding author: Tel: +33495450674; fax: +33495450154. E-mail address: gianetti@univ-corse.fr

S. Herbette

INRA, UMR 547 PIAF, F-63100 Clermont-Ferrand, France

S. Herbette

Clermont Université, Université Blaise Pascal, UMR 547 PIAF, BP 10448, F-63000 Clermont-Ferrand, France

P. Ollitrault

CIRAD, UPR 75, Avenue Agropolis, TA A-75/02, F-34398 Montpellier cedex 5, France

\begin{abstract}
Citrus plants originate from southeastern Asia, in a large area with various climates characterized by a broad range of temperatures. Some species have been diversified in temperate climates, others in subtropical climates. Temperature is assumed to be a key factor in citrus species adaptation and diversification of basic cellular functions. In a field experiment, the tolerance of the three fundamental Citrus species $C$. medica L., $C$. reticulata Blanco and C. maxima (Burm.) Merr., and Fortunella japonica (Thunb.) Swing. to photooxidative stress caused by seasonal climatic changes was evaluated on adult trees by measuring net photosynthesis $(P$ net $)$, stomatal conductance $(G \mathrm{~s})$, maximum photosynthesis $(P \max )$ and chlorophyll fluorescence $(F \mathrm{v} / F \mathrm{~m})$. In addition, seasonal changes in oxidative status, antioxidant enzymes (superoxide dismutase, catalase, ascorbate peroxidase, monodehydroascorbate reductase, dehydroascorbate reductase and glutathione reductase) and antioxidant metabolites (ascorbate and glutathione) were monitored. Mandarin and pummelo appeared to be the most tolerant, showing the lowest down-regulation of photosynthetic parameters, and the lowest accumulation of oxidized compounds associated with efficiency of their antioxidant system. Kumquat showed intermediate behaviour, with a large diminution of photosynthetic parameters and marked accumulation of hydrogen peroxide, whereas the malondialdehyde content remained low, with a strong induction of glutathione synthesis. Finally, citron appeared to be the most sensitive genotype with a marked decrease in photosynthetic performance, the largest accumulation of oxidative parameters, insufficient induction of antioxidant enzymes and down-regulation of ascorbate and glutathione synthesis.
\end{abstract}

Keywords Antioxidant enzymes, Antioxidant metabolites, Citrus, Oxidative status, Photosynthetic parameters, Seasonal climatic changes 


\section{Introduction}

The citrus plants belong to the subtribe Citrineae of the tribe Citreae in the subfamily Aurantioideae of the Rutaceae family (Webber et al. 1967) . Strictly, true citrus plants comprise six genera: Clymenia, Eremocitrus, Microcitrus, Poncirus, Fortunella and Citrus (Swingle and Reece 1967). Scora (1975) and Barrett and Rhodes (1976) considered that Citrus medica L.(citron), C. maxima (Burm.) Merr. (pummelo) and C. reticulata Blanco (mandarin) were the three fundamental species of Citrus. Nicolosi et al. (2000) added a fourth species, C. micrantha Wester, involved in the genesis of the lime (C. aurantifolia (Christm.) Swing.). Recently, this addition has gained support from various biochemical and molecular studies (Federici et al. 1998; Nicolosi et al. 2000; Barkley et al. 2006; Fanciullino et al. 2006). Citrus, Poncirus and Fortunella are believed to have their primary center of origin in south and southeastern Asia. In particular, $C$. medica originates from an area covering northeastern India, Burma, and western China; C. reticulata from Vietnam, southern China, and Japan; $C$. maxima from the tropical region of Malaysia and Indonesia; Poncirus from Chinese provinces close to the Himalayas and Fortunella from southeastern China (Swingle and Reece 1967; Scora 1975; Gmitter and Hu 1990; Mabberley 2004). This allopatric evolution has resulted in strong genetic and also phenotypic differentiation between these Citrus taxa (Garcia-Lor et al. 2012). Thus each species had initially to develop specific physiological and biochemical determinants, depending on climatic conditions in these areas of origin, that allowed their cultivation in different parts of the world, particularly at the northern limit of Mediterranean agriculture.

The Mediterranean climate, with its characteristic seasonality, provides a useful opportunity to study the adaptation of these species relative to their climate areas of origin. In this region, the summer season is characterized by high temperatures and dryness, whereas in winter, day temperature is generally moderate and night temperatures often dip below $5^{\circ} \mathrm{C}$.

Low temperatures can cause a number of physiological and biochemical dysfunctions to occur, such as a decrease in enzymatic activities participating in the Calvin cycle and reduced photosynthetic activity (Sevillano et al. 2009). Cold temperatures during winter inhibit the enzymatic reactions underlying $\mathrm{CO}_{2}$ fixation, but do not affect the light absorption ability of many overwintering evergreens such as citrus(Allen and Ort 2001; Ribeiro and Machado 2007). This results in photoinhibition or photooxidative damage or both (Oquist and Huner 2003). Such dysfunction has been found in citrus plants in other environmental conditions (Veste et al. 2000; Medina et al. 2002; Jifon and Syvertsen 2003), although the genetic response of true citrus species to chilling conditions is unknown.

Cold temperatures reduce $\mathrm{CO}_{2}$ availability and may decrease the $\mathrm{CO}_{2} / \mathrm{O}_{2}$ ratio in chloroplasts (Foyer and Noctor 2000). This condition facilitates electron flow to molecular oxygen $\left(\mathrm{O}_{2}\right)$ and superoxide anion $\left(\mathrm{O}_{2}{ }^{--}\right)$ production by the Mehler reaction (Foyer and Noctor 2003). Overproduction of ROS in plant cells under stress can damage cell components, including DNA, proteins and membrane lipids (Mittler 2002).

Plants have evolved efficient antioxidant systems that can protect them from the damaging effects of oxidative stress (Asada 1999) even at low temperatures induced by seasonal climatic changes (Polle and Rennenberg 1992; Verhoeven et al. 2005; Wang et al. 2009). These antioxidant mechanisms employ (i) ROSscavenging enzymes, such as superoxide dismutase (SOD, EC 1.15.1.1), catalase (CAT, EC 1.11.1.6), ascorbate peroxidase (APX, 1.11.1.11), (ii) recycling enzymes of ascorbate-glutathione cycle such as monodehydroascorbate reductase (MDHAR, EC 1.6.5.4), dehydroascorbate reductase (DHAR, EC 1.8.5.1) and 
glutathione reductase (GR, EC 1.6.4.2) and (iii) low molecular weight antioxidants, such ascorbic acid (Asa) and glutathione (Gsh).

In this study, seasonal climatic changes were used to analyze the response to chilling conditions of four ancestral species of Citrus and Fortunella originating from dispersed native areas in southeastern Asia, and selected for their ranging behaviour with respect to freezing injuries. Although it is considered to be very tolerant to freezing temperatures, the trifoliate orange (Poncirus trifoliata (L.) Raf.) was not included in this study because, unlike other citrus species, it is deciduous in winter. This behaviour is a form of physiological adaptation to low temperatures but lies outside our study. Among the evergreen citrus species, kumquat (Fortunella) is thought to be the most tolerant to freezing temperatures (can withstand $-15{ }^{\circ} \mathrm{C}$ ), while citron is considered to be one of the most vulnerable. Pummelos, diversified in tropical regions, are also known to be vulnerable to negative temperatures and mandarins to be more tolerant (Yelenosky 1985). This sample of citrus species was intended to be representative of different physiological reactions when evergreen citrus trees are exposed to chilling conditions. The aim of this study was to investigate the effect of broader seasonal temperature variation on citrus photosynthesis regulation and protective mechanisms against oxidative stress.

\section{Materials and methods}

Plant material and growth conditions

Experiments were carried out on leaves from 8-year-old trees of genotypes belonging to the Citrus and Fortunella genera (Table 1) growing in the experimental orchards of the Station de Recherches Agronomiques INRA-CIRAD of San Giuliano, Corsica, France (42 $12^{\prime} 55^{\prime \prime}$ N, 9 $9^{\circ} 29^{\prime} 29^{\prime \prime}$ E; 51m a.s.1., under a Mediterranean climate and on soil derived from alluvial deposits and classified as fersiallitic, pH range 6.0-6.6). Trees were spaced at $6 \times 4 \mathrm{~m}$ and were subjected to homogenous growing conditions to reduce environmental effects. Water was supplied every day on the basis of $100 \%$ replacement of actual evapotranspiration estimated from the equation of Penman-Monteith (1965). Fertilizers were supplied and insects and diseases controlled according to the recommendations of the local department of agriculture.

The experiment in orchards was conducted on 20-21 September 2010 (ambient air temperature $25^{\circ} \mathrm{C}$ ) and in January 2011 (ambient air temperature $6^{\circ} \mathrm{C}$ ) on one genotype of each of the three basic true species of the Citrus genus and on one genotype of the Fortunella genus (Table 1). Average daily minimum air temperatures for each of the months from July to January were $18.6{ }^{\circ} \mathrm{C}, 16.9{ }^{\circ} \mathrm{C}, 13.8^{\circ} \mathrm{C}, 10.9{ }^{\circ} \mathrm{C}, 6.6{ }^{\circ} \mathrm{C}, 4.1^{\circ} \mathrm{C}$ and $4.6{ }^{\circ} \mathrm{C}$, respectively. Average daily global radiation for each of the months from July to January at this location was $2559,2157,1725,942,685,546$ and $579{\mathrm{~J} . \mathrm{cm}^{-2}}^{2}$. For each genotype, three individual trees growing in the same field were used. For physiological parameter measurements, the same leaves were used. On each tree, three fully expanded leaves from spring of the current year's growth were selected in September (end of summer, warm period) and January (winter, cold period). Thus nine measurements per genotype were made on sunny mornings of each season (between 08:00h and 12:00h). For biochemical assays, on each of the three trees of a genotype, two samples of 15 fully expanded leaves from the current year's growth were collected on sunny mornings (between 08:00h and 12:00h) of each specific sampling date and immediately frozen in liquid nitrogen and stored at $-80^{\circ} \mathrm{C}$. Thus six samples of 15 leaves were separately analyzed for each genotype and for each season. 
Before analysis, each leaf sample was ground to a fine powder in liquid nitrogen using a pre-chilled pestle and mortar.

The experiment under controlled conditions was performed on detached leaves from the same trees of each genotype (Table 1) in September 2011. On each tree, two fully expanded leaves of the current year's growth were collected on sunny mornings. Thus six leaves per genotype were collected and incubated independently in closed Petri dishes containing tissue paper moistened with distilled water. Petri dishes were then transferred for 72 hours before cold treatment to a growth chamber in which the temperature was set at $25{ }^{\circ} \mathrm{C}$ (equivalent to orchard ambient air temperatures during September experiments). The cold treatment was imposed by shifting the temperature of the growth chamber to $6{ }^{\circ} \mathrm{C}$ (equivalent to orchard ambient air temperatures during January experiments), $3 \mathrm{~h}$ after the beginning of the day period and for a period of $72 \mathrm{~h}$. A similar experiment was performed on detached leaves maintained at $25^{\circ} \mathrm{C}$ for at least $168 \mathrm{~h}$ to check the absence of changes in Pnet. The relative humidity was maintained at $85 \%$ for both temperature conditions. The photoperiod was $16 \mathrm{~h}$ and photon flux density was provided by cool fluorescent lamps $\left(350 \mu \mathrm{mol} \cdot \mathrm{m}^{-2} \cdot \mathrm{s}^{-1}\right)$. Three measurements per genotype were made at each temperature. Air temperature, relative humidity and light level were continuously monitored at $1 \mathrm{~h}$ intervals in growth chambers throughout the entire experiment.

Gas exchange measurements

Measurements of net photosynthetic rate (Pnet), stomatal conductance $(G s)$ and maximum photosynthetic rate $(P \max )$ were determined with a portable open gas exchange system (GFS 3000, WALZ, Effeltrich, Germany). Air flow rate was $750 \mu \mathrm{mol} . \mathrm{s}^{-1}$. In a gas exchange chamber, photosynthetic photon flux density (PPFD) was controlled using a LED radiation source and was fixed at a PPFD of $1400 \mu \mathrm{mol} \cdot \mathrm{m}^{-2} \cdot \mathrm{s}^{-1}$ for Pnet and $G$ s or at a saturated PPFD of $2000 \mu \mathrm{mol} \cdot \mathrm{m}^{-2} \cdot \mathrm{s}^{-1}$ for $P$ max. The use of this LED source ensured a constant, uniform light across all measurements. Carbon dioxide concentration was set at $380 \mu \mathrm{mol}^{-\mathrm{mol}^{-1}}$ for $P$ net and $G$ s measurements and at $2000 \mu$ mol.mol $^{-1}$ for $P$ max measurements.

\section{Chlorophyll a fluorescence measurements}

In vivo chlorophyll fluorescence was measured on sunny days on the same leaves previously used for gas exchange measurements using a portable chlorophyll fluorometer (Hansatech, Norfolk, England). Intact leaves were dark-adapted with leaf clips for $20 \mathrm{~min}$ to allow relaxation of fluorescence quenching associated with thylakoid membrane energization (Krause et al. 1983). Minimal fluorescence $\left(F_{0}\right)$ and maximal fluorescence $(F \mathrm{~m})$ were obtained by imposing a $1 \mathrm{~s}$ saturating flash to reduce all the PSII reaction centers. The maximum potential photochemical efficiency of PSII was expressed as the ratio $F \mathrm{v} / F \mathrm{~m}(=(F \mathrm{~m}-F \mathrm{o}) / F \mathrm{~m})$. The degree of photoinhibition was evaluated by the reduction in the value of $F \mathrm{v} / F \mathrm{~m}$. Seasonal data were collected on sunny mornings at $08: 30 \mathrm{~h}$ for each month (ambient air temperature respectively $16.4{ }^{\circ} \mathrm{C}$ and $5.3{ }^{\circ} \mathrm{C}$ ).

Measurement of $\mathrm{H}_{2} \mathrm{O}_{2}$ and MDA 
$\mathrm{H}_{2} \mathrm{O}_{2}$ levels were measured following the protocol described by Zhou B. et al. (2006). For extraction, $200 \mathrm{mg}$ of frozen leaf powder was homogenized in $3 \mathrm{~mL}$ of trichloroacetic acid (TCA) $5 \%$ (w:v) containing $60 \mathrm{mg}$ of activated charcoal. The mixture was then centrifuged at $5000 \times \mathrm{g}$ for $20 \mathrm{~min}$ at $4{ }^{\circ} \mathrm{C}$.

The MDA content of leaves was determined using a thiobarbituric acid (TBA) reaction described by Hodges et al. (1999). For extraction, $100 \mathrm{mg}$ of frozen leaf powder was homogenized with inert sand in $2.5 \mathrm{~mL}$ of $80 \%$ ethanol (v/v), followed by centrifugation at $3000 \times g$ for $10 \mathrm{~min}$ at $4{ }^{\circ} \mathrm{C}$.

All the measurements were performed using a V-630 spectrophotometer (Jasco Inc., Tokyo, Japan).

Assay of antioxidant enzymes activities

Frozen leaf powder was homogenized in extraction medium (100 mM potassium phosphate buffer, pH 7.5, containing $0.1 \%(\mathrm{v} / \mathrm{v})$ TritonX-100 and $1 \%(\mathrm{w} / \mathrm{v})$ polyvinylpyrollidone (PVP) for all enzymatic assays) using $27 \mathrm{mg}$ FW per $\mathrm{mL}$ of buffer. The homogenate was then centrifuged at $13,000 \times g$ for $30 \mathrm{~min}$ at $4{ }^{\circ} \mathrm{C}$. The supernatant was used for the protein and enzyme analysis (except for SOD where the extract was diluted 20-fold). Protein concentration was determined by the method of Bradford (Bradford 1976). All kinetic measurements were performed using a V-630 spectrophotometer (Jasco Inc., Tokyo, Japan).

Superoxide dismutase (SOD, EC 1.15.1.1) activity was measured using a modified method of Oberley and Spitz (1984). $100 \mu \mathrm{L}$ of diluted extract was added to a solution containing $1 \mathrm{mM}$ DETAPAC buffer (pH 7.8), 1.25 units of catalase, $0.07 \mathrm{mM} \mathrm{NBT}, 0.2 \mathrm{mM}$ xanthine and 0.010 units of xanthine oxidase in a total volume of $1.0 \mathrm{~mL}$. One unit of SOD was defined as the amount of enzyme causing 50\% inhibition of the rate of NBT reduction at $560 \mathrm{~nm}$, at $25^{\circ} \mathrm{C}$.

Catalase (CAT, EC 1.11.1.6) activity was measured according to the method of Aebi (1984). The reaction mixture $(1.1 \mathrm{~mL})$ contained $100 \mu \mathrm{L}$ of crude enzyme extract, $37.8 \mathrm{mM}$ sodium phosphate buffer $(\mathrm{pH} 7.0)$ and $4.4 \mathrm{mM} \mathrm{H}_{2} \mathrm{O}_{2}$. The decrease in absorbance was measured at $240 \mathrm{~nm}\left(\varepsilon=39.4 \mathrm{mM}^{-1} . \mathrm{cm}^{-1}\right)$. One unit of CAT was expressed as $1 \mu \mathrm{mol} \mathrm{H}_{2} \mathrm{O}_{2}$ degraded per min at $25^{\circ} \mathrm{C}$.

Ascorbate peroxidase (APX, EC 1.11.1.11) activity was determined according to a modified method described by Asada (1984). The standard reaction mixture $(1.0 \mathrm{~mL})$ contained $0.17 \mathrm{mM}$ ascorbate, $33 \mu \mathrm{L}$ of crude enzyme extract in a $60.3 \mathrm{mM}$ potassium phosphate buffer ( $\mathrm{pH}$ 7.0). The reaction was triggered when $4.95 \mathrm{mM} \mathrm{H} \mathrm{H}_{2} \mathrm{O}_{2}$ was added. The rate of ascorbate oxidation was evaluated at $290 \mathrm{~nm}$ for $3 \mathrm{~min}(\varepsilon=$ $2.8 \mathrm{mM}^{-1} . \mathrm{cm}^{-1}$ ). One unit of APX was expressed as the oxidation of $1 \mu \mathrm{mol}$ ascorbate per min at $25^{\circ} \mathrm{C}$.

Monodehydroascorbate reductase (MDHAR, EC 1.6.5.4) activity was established by monitoring the MDHAdependent oxidation of NADH according to the method of Drew et al. (2007), slightly modified. $100 \mu \mathrm{L}$ of crude enzyme extract was added to a solution containing $9.7 \mathrm{mM}$ potassium phosphate, $0.125 \%$ Triton X100 (pH 8), $2.5 \mathrm{mM}$ ascorbate, 0.128 units of ascorbate oxidase in a total volume of $1.0 \mathrm{~mL}$. The reaction was started by adding $0.2 \mathrm{mM}$ NADH. The decrease in absorbance was measured at $340 \mathrm{~nm}\left(\varepsilon=6.3 \mathrm{mM}^{-1} \cdot \mathrm{cm}^{-1}\right)$. One MDHAR unit was defined as the amount of enzyme required to oxidize $1 \mu \mathrm{mol} \mathrm{NADH}$ per min at $340 \mathrm{~nm}$ at $25^{\circ} \mathrm{C}$.

Dehydroascorbate reductase (DHAR, EC 1.8.5.1) activity was assayed by measuring the rate of appearance of ascorbate measured at $265 \mathrm{~nm}\left(\varepsilon=14.5 \mathrm{mM}^{-1} . \mathrm{cm}^{-1}\right)(1984)$. The standard reaction mixture $(1.0 \mathrm{~mL}) \mathrm{contained}$ $41 \mathrm{mM}$ potassium phosphate buffer ( $\mathrm{pH}$ 6.5), $5 \mathrm{mM}$ Gsh, $0.11 \mathrm{mM}$ EDTA, and $75 \mu \mathrm{L}$ of crude enzyme extract, 
with $0.5 \mathrm{mM}$ DHA added to initiate the reaction. One DHAR unit was defined as the amount of enzyme that allowed the formation of $1 \mu \mathrm{mol}$ ascorbate per min at $25^{\circ} \mathrm{C}$.

Glutathione reductase (GR, EC 1.6.4.2) activity was measured according to the modified method of Smith et al. (1988). The standard reaction mixture $(1.0 \mathrm{~mL})$ contained $50 \mathrm{mM}$ potassium phosphate buffer $(\mathrm{pH} 7.0)$, $1 \mathrm{mM}$ GssG, $0.75 \mathrm{mM}$ DTNB and $100 \mu \mathrm{L}$ of crude enzyme extract. $0.1 \mathrm{mM}$ NADPH was added to initiate the reaction. The increase in absorbance due to the formation of TNB was measured at $412 \mathrm{~nm}(\varepsilon=$ $\left.14.15 \mathrm{mM}^{-1} . \mathrm{cm}^{-1}\right)$. One GR unit was defined as the amount of enzyme that allowed the formation of $1 \mu \mathrm{mol}$ TNB per min at $25^{\circ} \mathrm{C}$.

Assay of antioxidant metabolites

Total ascorbate (tAsa) and reduced ascorbate (Asa) contents were measured according to the method of Gillespie and Ainsworth (2007). For extraction, $40 \mathrm{mg}$ of frozen leaf powder was homogenized in $2.0 \mathrm{~mL}$ of a $6 \%(w / v)$ TCA solution and centrifuged at $13,000 \times g$ for 5 min at $4{ }^{\circ} \mathrm{C}$.

Total glutathione (tGsh) and oxidized glutathione (GssG) contents were measured according to the DTNBGR recycling procedure of Rahman et al. (2006). For extraction, $50 \mathrm{mg}$ of frozen leaf powder was homogenized in $2.0 \mathrm{~mL}$ of mixed buffer $(100 \mathrm{mM}$ potassium phosphate, $\mathrm{pH} 7.5,5 \mathrm{mM}$ EDTA, $0.1 \%(\mathrm{v}: \mathrm{v})$ Triton X-100 and

$23 \mathrm{mM}$ sulfosalicylic acid) and centrifuged at $8000 \times g$ for $10 \mathrm{~min}$ at $4{ }^{\circ} \mathrm{C}$.

All measurements were performed using a V-630 spectrophotometer (Jasco Inc., Tokyo, Japan).

\section{Statistical analyses}

The experimental designs were split-plot with genotype as the main plot and season (or temperature for the second experiment) as the subplot. Differences between genotypes and seasons were analyzed with two-way ANOVA and comparisons between means were made with the least significant difference (LSD) test at $P<0.05$ using R statistical software (http://www.R-project.org).

\section{Results}

Seasonal changes in Pnet and Gs

Responses of Pnet and $G$ s for the four species were established on 20-21 September 2010 (warm period) and 4-5 January 2011 (cold period) (Fig. 1; Table 2). Based on warm period results, several differences could be observed on the photosynthetic behaviour of the different varieties studied, CC and MK having the highest Pnet and Gs and WLM and PP having the lowest Pnet and Gs (Fig. 1a, b). In the cold period, the reduction in Pnet and $G$ s was significantly greater in $\mathrm{CC}$ and $\mathrm{MK}$ compared with the warm period ( $-64 \%$ and $\sim-78 \%$ for $P$ net, respectively; $\sim-53 \%$ and $\sim-67 \%$ for $G$ s, respectively) than in WLM and PP ( - 25\% and $\sim-31 \%$ for Pnet, respectively; -34\% and $\sim-33 \%$ for Gs, respectively) (Fig. 1a, b).

Comparison of Pnet under orchard climatic conditions and controlled conditions 
To check that seasonal changes observed in the Pnet values under orchard conditions were due to temperature variations and not to leaf senescence, we also measured the previous parameter in the same genotypes under controlled conditions at $6{ }^{\circ} \mathrm{C}$ and $25^{\circ} \mathrm{C}$. Comparing the Pnet values measured under controlled conditions in September 2011 at the same temperature as those obtained in September 2010 (Fig. 2a) and January 2011 (Fig. 2b) in the orchards, no significant difference was found, whatever the genotype, between the two mean values for each treatment (attached leaves $v s$. detached leaves). Likewise, no significant variation was observed for $G$ s between attached and detached leaves (data not shown).

Seasonal changes in photosynthetic traits

$F \mathrm{v} / F \mathrm{~m}$ was lower in the cold period for all genotypes, especially when temperatures were close to $0{ }^{\circ} \mathrm{C}$ (Fig. 3a; Table 2). The leaves of $\mathrm{CC}$ and MK had significantly lower $F \mathrm{v} / F \mathrm{~m}$ compared with the warm period ( $-25 \%$ and $\sim-22 \%$, respectively) and were consequently more photoinhibited than leaves of WLM and PP $(\sim-15 \%$ and $\sim-10 \%$, respectively) .

$P \max$ decreased significantly in the cold period in all the genotypes (Fig. 3b; Table 2), and this reduction was greater in CC and MK ( -53\% and -73\%, respectively) than in WLM and PP ( -39\%).

Seasonal changes in the oxidative status and antioxidant system

$\mathrm{H}_{2} \mathrm{O}_{2}$ and MDA content increased in all the genotypes from the warm to the cold period (Figs. 4a, b; Table 2), indicating that all the genotypes were subjected to oxidative stress. CC and MK maintained relatively higher levels of leaf $\mathrm{H}_{2} \mathrm{O}_{2}$ than WLM and PP in the cold period. CC showed higher basal values of MDA in the warm period and in the cold period, indicating a higher lipid peroxidation level. In addition, in the cold period, its values reached a very high level compared with the other genotypes and especially MK ( 3 times higher).

We analyzed the activities of various enzymes acting as ROS scavengers, i.e. SOD, CAT and APX (Fig. 5; Table 2) or ensuring the supply/regeneration of primary antioxidants, i.e. MDHAR, DHAR and GR (Fig. 6; Table 2). Highly variable patterns of enzymatic activity were observed among genotypes.

SOD activity increased slightly in all genotypes from the warm to the cold period (Fig. 5a), from $~ 1.12$ times higher for PP to 1.27 times higher for MK. Basal CAT levels were higher in CC and MK (54.4 and $39.1 \mu \mathrm{mol} . \mathrm{min}^{-1} \cdot \mathrm{mg}^{-1}$ protein, respectively) than in WLM and PP (13.2 and $19.2 \mu \mathrm{mol} \cdot \mathrm{min}^{-1} \cdot \mathrm{mg}^{-1} \mathrm{protein}$, respectively). All the genotypes studied significantly depressed CAT activity in response to cold climatic conditions (Fig. 5b). The loss of activity was more substantial in the leaves of CC, MK and WLM ( -45\%, $\sim-54 \%$ and $\sim-65 \%$, respectively) than in PP $(\sim-24 \%)$. APX activity was enhanced significantly in all the citrus genotypes from the warm to the cold period $(\sim 2.4-, \sim 1.75-$ and $\sim 1.77$-fold increase for CC, MK and PP, respectively) except for WLM, where no significant changes were found (Fig. 5c).

Seasonal changes had a significant effect on MDHAR activity in MK and PP ( 2.9 and 1.6 times higher in the cold than in the warm period, respectively). No significant difference for CC and WLM was found (Fig. 6a). However, MDHAR activity in WLM was similar to PP and MK in the cold period and significantly higher than in CC. Considering DHAR activity, the increase between the warm and the cold period was identical whatever 
the genotype concerned (from $\sim 1.21$ - to $\sim 1.59$-fold increases for PP and CC, respectively) (Fig. 6b). The pattern of regulation of GR differed according to genotype. Whereas WLM showed a slight diminution ( - $17 \%)$ in the cold period, CC and MK showed significantly contrasting increases ( 2.1 and $\sim 1.4$ times higher, respectively) (Fig. 6c). GR activity in PP showed no significant difference between the two periods, but its level was similar to CC and MK in the cold period. Overall, WLM and PP had significantly higher basal levels of the three recycling enzymes of the ascorbate-glutathione cycle during the warm period than CC and MK.

In the cold period conditions, leaves of the four studied varieties accumulated significantly higher levels of tAsa, Asa and DHA than in the warm period conditions (Table 2, Table 3). For tAsa and DHA, a significant separation of MK had been observed with larger increases ( 1.78 and $\sim 2.84$ times higher, respectively) than the other genotypes (except CC for tAsa) in which the enhancements were equivalent. No greater increase in one genotype compared with another was found for Asa. Leaf redox Asa/DHA ratio decreased for all genotypes from the warm to the cold period. A significant sharp decrease was observed in MK ( -57\%) due to a larger amount of DHA which unbalanced redox status. In other genotypes, the decline was much lower ( - 29\% in CC, -27\% in WLM and -19\% in PP). However, only CC exhibited a value less than 1. tGsh, Gsh and GssG contents were always higher in the cold period (Table 2, Table 4). MK showed significantly higher increases than other genotypes, particularly for tGsh and Gsh ( $\sim 3.53$ and $\sim 4.43$ times higher than warm period values). GssG, the oxidized form of glutathione, accumulated more intensively in CC and MK ( 2.58- and $~ 2.70$-fold increases, respectively) than in WLM and PP. However, a different pattern of regulation of the redox status was observed. Whereas MK showed a significant increase in Gsh/GssG ratio ( 1.72 times higher compared with the warm period), the ratio remained unchanged in WLM and PP and was depleted in CC ( $-40 \%$ compared with the warm period).

\section{Discussion}

The successive cellular events that occur in chilling conditions have often been investigated in different species under controlled conditions (Lim et al. 2009; Bonnecarrere et al. 2011). The main studies have been conducted on deciduous species in which cold treatments were applied abruptly in a growth chamber, with no transition period and under conditions of constant growth. Also, there is still a debate on how best to chill sensitive plant species to model cold temperatures. Here we investigated the effect of seasonal climatic changes on the photosynthesis and antioxidant system in evergreen varieties from ancestral species of citrus in a marginal zone of their areas of origin. We found ranging chilling response among the different citrus genotypes studied.

Seasonal changes in photosynthetic components and photoinhibition

Citrus species have generally a low temperature threshold of around $13{ }^{\circ} \mathrm{C}$, with photosynthetic metabolism being severely disrupted at lower temperatures (Ribeiro and Machado 2007). During the experimental period, minimum air temperature fluctuated around $15{ }^{\circ} \mathrm{C}$ in September and around $4.5^{\circ} \mathrm{C}$ in January. Thus measurements carried out in September 2010 could correspond to the regular photosynthesis of citrus given their areas of origin. Net photosynthetic rate (Pnet), stomatal conductance $(G \mathrm{~s})$, chlorophyll fluorescence $(F \mathrm{v} / F \mathrm{~m})$ and maximum photosynthetic rate $(P \max )$ measurements have been commonly used to investigate the effect of 
seasonal climatic changes on the functioning of the photosynthetic system (Maxwell and Johnson 2000; Oquist and Huner 2003). Under warm conditions, photosynthesis of MK, WLM and PP were clearly stomata-controlled, and the interspecific dissimilarities appeared to be mainly due to differences in stomatal aperture. However, photosynthesis of $\mathrm{CC}$ might be either stomata-controlled or limited by the external $\mathrm{CO}_{2}$ concentration alone (380 $\mu$ mol.mol $\left.{ }^{-1}\right)$. The lower photosynthetic activity observed in all the genotypes in the cold period might be explained by both a closure of stomata and low temperature (Figs. 1, 3). According to Allen and Ort (2001), the decline in photosynthesis during chilling stress in warm-climate plants is caused by stomatal closure, which compromises gas exchange and $\mathrm{CO}_{2}$ fixation, and the loss of enzymatic activities participating in the Calvin cycle. Low temperature, which occurs at night in both air and soil, is therefore an environmental factor that affects plant physiology (Allen and Ort 2001). In 'Valencia' sweet orange, Ribeiro et al. (2009) had previously observed, during seasonal climatic changes, that lower temperatures led to a decrease in stomatal conductance with a drop in photosynthetic activity. A decrease in $\mathrm{CO}_{2}$ assimilation linearly with stomatal conductance reduction had already been observed during other abiotic stress such as drought stress in 'Swingle' citrumelo (de Campos et al. 2011), salt stress in Cleopatra mandarin (Anjum 2010) and chilling stress in 'Valencia' sweet orange (Santos et al. 2011). Seasonal results of Pnet were confirmed by our experiments conducted on detached leaves at $6{ }^{\circ} \mathrm{C}$. Pnet measurements obtained on detached leaves suggested that the temperature sensitivity of Calvin cycle enzymes was probably responsible for the drop in photosynthesis (Holaday et al. 1992). It was therefore possible to exclude an effect of leaf senescence in orchards from September to January. Although trifoliate orange rootstock is known for its relative resistance to cold compared with Volkamer lemon (Yelenosky 1985), these measurements on detached leaves also enabled us to exclude an effect of rootstock on the photosynthetic parameters estimated in the orchard, as no variation was observed between attached and detached leaves. The decline of photosynthesis at low temperature has been previously observed in "Valencia" sweet orange placed in a growth chamber where air temperatures were similar to a typical winter day under a Mediterranean climate (Santos et al. 2011). Thus the greater decrease in Pnet, Gs, Fv/Fm and $P$ max in CC and MK than in WLM and PP could suggest a greater sensitivity to cold, as previously shown in Hevea, another chill-sensitive species (Mai et al. 2010). This implies that leaves become progressively less efficient at processing the incident photon flux, possibly related to an increased proportion of closed, reversibly inactivated or destroyed photosystem II reaction centers resulting from enhanced ROS accumulation (Grover et al. 1986). During waterlogging stress, Arbona et al. (2009) demonstrated that Cleopatra mandarin, a flooding-sensitive rootstock, exhibited severe reductions in Pnet, $G \mathrm{~s}$ and $F \mathrm{v} / F \mathrm{~m}$, while Carrizo citrange, a flooding-tolerant rootstock, showed only small differences from control. Conversely, during salt stress, Brumos et al. (2009) established that Cleopatra mandarin, a salt-tolerant rootstock, exhibited a greater decrease in these three parameters than the salt-sensitive Carrizo citrange. They showed that Cleopatra mandarin induced greater stress responses in gene expression while repressing central metabolic processes such as photosynthesis. For instance, different chitinases, involved in defense responses, were strongly induced in Cleopatra mandarin and repressed in Carrizo citrange. Thus studying the response of physiological parameters is a first step in the evaluation of tolerance or sensitivity that must be extended by a biochemical analysis of antioxidant systems.

Leaf antioxidant systems and photoprotection 
Excitation energy not used for photochemistry can be transferred to $\mathrm{O}_{2}$, resulting in the production of ROS such as superoxide anion $\left(\mathrm{O}_{2}{ }^{-}{ }^{-}\right)$and hydrogen peroxide $\left(\mathrm{H}_{2} \mathrm{O}_{2}\right)$. The increased level of $\mathrm{H}_{2} \mathrm{O}_{2}$ in winter, particularly in $\mathrm{CC}$ and $\mathrm{MK}$, could be due to higher superoxide radical dismutation in the presence of a reductant or elevated synthesis and (or) decreased activity of CAT and (or) APX. It is noteworthy that leaf $\mathrm{H}_{2} \mathrm{O}_{2}$ content increased linearly with decreasing $\mathrm{CO}_{2}$ assimilation in all the genotypes. The changes in MDA content are an indicator of lipo-peroxidation caused by ROS. The larger increase in this parameter in CC is consistent with its probably greater sensitivity and vulnerability to photooxidation previously noted. In addition, the lower accumulation of MDA content in MK suggests an efficient scavenging of ROS. There may also be a putative relationship between lower $\mathrm{H}_{2} \mathrm{O}_{2} / \mathrm{MDA}$ levels and higher tolerance to stress. The occurrence of an $\mathrm{H}_{2} \mathrm{O}_{2}$ and MDA burst had previously been observed in citrumelo under waterlogging stress (Hossain et al. 2009), and in two rice genotypes under low temperature stress (Bonnecarrere et al. 2011).

To cope with elevated levels of ROS, aerobic cells have evolved a range of enzymatic and non-enzymatic antioxidant reactions. In several studies, the antioxidant enzyme response as indicative of tolerance or sensitivity has been explored, and has shown a direct relationship between increased antioxidant activity and stress tolerance (Arbona et al. 2008; Hossain et al. 2009). Specific modifications to the enzymatic complement of cells overcome the metabolic challenge of cold temperatures in vivo. For instance, the cell can (i) produce more enzymes to maintain adequate activity, (ii) increase the activation state or (iii) generate new isozyme forms with enhanced catalytic function (Guy 1999). Among antioxidant enzymes, SOD forms the first line of defense against ROS and is located in many subcellular compartments (Gill and Tuteja 2010). Our results show an increase in SOD activity in all the genotypes with the same pattern as previously shown in citrumelo, Carrizo citrange and Cleopatra mandarin under waterlogging stress (Arbona et al. 2008) or in Rhododendron species under chilling stress (Wang et al. 2009). According to its cellular localization, $\mathrm{H}_{2} \mathrm{O}_{2}$ produced during SOD reaction can then be metabolized into oxygen and water by CAT in peroxisomes (Foyer et al. 1994) or by APX using Asa as electron donor in the chloroplasts, mitochondria and cytosol (Foyer and Noctor 2000). Unexpectedly, CAT decreased in all the genotypes studied as previously reported in 'Sour' pummelo and 'Xuegan' orange grown under magnesium-deficiency by Yang et al. (2012). The decline in CAT activity could be a consequence of its sensitivity to light and its low temperature lability (Hertwig et al. 1992). Its photoinactivation can also be caused by oxidative damage initiated in the chloroplast via direct absorption of light by the heme moieties of the enzyme itself (Shang and Feierabend 1999). These data suggest that the reduced CAT activity observed at low temperatures during January can account for accumulation of ROS such as $\mathrm{H}_{2} \mathrm{O}_{2}$. APX isoforms were induced to compensate for deficiencies in CAT activity (Palatnik et al. 2002). In this study, the increase in total APX activity did not compensate for the impaired CAT activity, as $\mathrm{H}_{2} \mathrm{O}_{2}$ accumulated as previously reported in Hevea during chilling stress (Mai et al. 2010) or in citrumelo during waterlogging stress (Hossain et al. 2009). However, it could be sufficient to prevent a lethal accumulation of $\mathrm{H}_{2} \mathrm{O}_{2}$ if we consider the lower MDA accumulation in MK, WLM and PP compared with CC. These results are consistent with previous reports on two flooding-tolerant rootstocks (Arbona et al. 2008).

The antioxidants Asa and Gsh are crucial for plant protection against oxidative stress (Noctor and Foyer 1998). It is believed that the redox status of these metabolites is essential for the proper scavenging of ROS in cells and it is therefore related to genotype tolerance. The ratio between reduced and oxidized forms of ascorbic acid is controlled by two enzymes, including monodehydroascorbate reductase (MDHAR) and dehydroascorbate 
reductase (DHAR), which hold the pool of reduced ascorbic acid. High significant levels of MDHAR in MK, WLM and PP compared with CC might be sufficient to maintain the ratio above 1 in winter. However, in CC, improving only DHAR activity did not prove sufficient to fight against chilling stress, as the ratio was below 1 . Thus the levels of MDHAR suggest that this enzyme may help to explain the differences in sensitivity to seasonal climatic changes. These results are in close agreement with experiments conducted on tomato fruits, where a positive correlation was observed between MDHAR activity and ascorbic acid content under chilling stress (Stevens et al. 2008). Consequently, to recycle ascorbic acid efficiently during chilling stress, an increased activity of both MDHAR and DHAR seem to be required. Generally, precise metabolic tuning of GR allows the cell to maintain the favourable Gsh/GssG ratio for cellular redox regulation. Despite a higher increase in GR activity and higher Gsh content in CC than in other genotypes, this increment might be insufficient to recycle Gsh pool efficiently, as the decrease in the ratio was very marked in the cold period. For the other genotypes, the maintenance or significant increase of Gsh/GssG ratio could additionally suggest de novo glutathione synthesis (Queval et al. 2007). Previous observations agree with those of Arbona et al. (2008), who demonstrated that during waterlogging stress, the most tolerant genotype, Carrizo citrange, was able to keep active forms of Asa and Gsh, while the most sensitive genotype, Cleopatra mandarin, found these responses impaired. Queval et al. (2007) demonstrated that in the Arabidopsis photorespiratory mutant cat2, glutathione appeared as a key modulator of $\mathrm{H}_{2} \mathrm{O}_{2}$ concentration. These results are consistent with the lowest accumulation of MDA in WLM, PP and MK. The higher basal levels of the three recycling enzymes in WLM and PP may explain, in part, the lower accumulation of stress indicators and oxidized forms of antioxidant metabolites observed during the warm period (essentially $\mathrm{H}_{2} \mathrm{O}_{2}$, MDA, DHA and GssG). Also, the strong production of $\mathrm{H}_{2} \mathrm{O}_{2}$ in $\mathrm{MK}$ and its strong ability to reduce cellular damage could be explained by an effective regulation of Asa-Gsh cycle and especially by the glutathione pool.

Relationships between genotype tolerance to cold photooxidative stress and geographical origins

As no information regarding the chilling behaviour of these genotypes was available in the literature, the extent of the decline in photosynthetic parameters, the accumulation of oxidative compounds and the increase in antioxidant performance in cold period allowed us to classify three of the four genotypes studied as 'sensitive' or 'tolerant'. Considering our results, PP and WLM showed the lowest loss of photosynthesis and photochemical performances, the lowest accumulation of oxidative stress indicators, and the effective activation of antioxidant defenses, mainly APX and glutathione (especially in PP). Hence these can be considered as the genotypes most tolerant to cold photooxidative stress. CC showed a large decrease in photosynthetic and photochemical parameters, a marked accumulation of $\mathrm{H}_{2} \mathrm{O}_{2}$ and MDA and an antioxidant system that responded to stress, but not effectively. This genotype can be classified as the one most sensitive to cold photooxidative stress. MK showed special behaviour with a large decrease in photosynthetic and photochemical parameters, a marked accumulation of $\mathrm{H}_{2} \mathrm{O}_{2}$ but not of MDA, and an efficient recycling of glutathione.

These conclusions are only partially in line with the hypothesis of a link between the geographical origins of the analyzed citrus species and the tree tolerance to chilling. The subtropical diversification area of citron could explain their greater sensitivity. The most northern origin of kumquat, and to a lesser extent of mandarin, could explain their greater adaptation to cold. However, by this argument, the tropical origin of pummelo should not 
have favoured its adaptation to chilling. This theoretical classification, based on origin areas, has been noted by some authors who have monitored leaf freezing tolerance (LFT) (Yelenosky 1985; Yelenosky and Guy 1989). This parameter is generally used to highlight the very important process in plants known as cold acclimation (CA). CA involves changes in gene expression and in many cellular processes that result in modified metabolic and biosynthetic pathways enabling tissues to survive cold or freezing conditions (Guy 1990). For example, pummelo, classified by Yelenosky (1985) as cold sensitive, can cold-acclimate to survive freezing at $-4{ }^{\circ} \mathrm{C}$ or $-5{ }^{\circ} \mathrm{C}$ (Moore et al. 2000). Thus differences in classification of pummelo between geographical origins and our results could also be explained by an efficient cold acclimation process in this genotype. Additionally, photosynthetic traits and antioxidant metabolism are sensitive to many different abiotic stresses, thereby also confounding the relationship between genotype tolerance to a specific stress and geographical origins.

In conclusion, the comparison of physiological and biochemical parameters carried out on genotypes from varying areas of origin and belonging to the three basic true species of Citrus and to genus Fortunella highlighted contrasting behaviours towards cold photooxidative stress induced by seasonal climatic changes. Four conclusions may be drawn: (i) the response of photosynthesis to photooxidative stress is strongly influenced by genetic factors, (ii) lower $F \mathrm{v} / F \mathrm{~m}$ values can be related to a greater sensitivity of genotypes, (iii) APX activity may be insufficient in sensitive genotypes to scavenge all $\mathrm{H}_{2} \mathrm{O}_{2}$ produced in excess and (iv) MDHAR and the redox status of Gsh and Asa appear crucial in preventing cell oxidative damage in cold resistant citrus genotypes. Despite their known sensitivity to cold, our results show different cold tolerance capabilities that could be exploited in breeding programs. Taking the present work as a reference, it is now possible to investigate and screen the cultivated citrus genotypes for their performance under a Mediterranean climate or in other area with cold periods.

Acknowledgments We thank the Collectivité Territoriale de Corse (CTC) for the financial support of this study. We are grateful to Anne-Laure Fanciullino and Isabelle Poggi for their assistance for leaf harvesting. We particularly thank Isabelle Tur and Jérôme Barbaggio for technical assistance in the grinding of leaves.

\section{References}

Aebi H (1984) Catalase in vitro. Methods Enzymol 105: 121-126

Allen DJ, Ort DR (2001) Impacts of chilling temperatures on photosynthesis in warm-climate plants. Trends Plant Sci 6: 36-42

Anjum MA (2010) Response of Cleopatra mandarin seedlings to a polyamine-biosynthesis inhibitor under salt stress. Acta Physiol Plant 32: 951-959

Arbona V, Hossain Z, Lopez-Climent MF, Perez-Clemente RM, Gomez-Cadenas A (2008) Antioxidant enzymatic activity is linked to waterlogging stress tolerance in citrus. Physiol Plant 132: 452-466

Arbona V, Lopez-Climent MF, Perez-Clemente RM, Gomez-Cadenas A (2009) Maintenance of a high photosynthetic performance is linked to flooding tolerance in citrus. Environ Exp Bot 66: 135-142

Asada K (1984) Chloroplasts - Formation of active oxygen species. Methods Enzymol 105: 422-429

Asada K (1999) The water-water cycle in chloroplasts: Scavenging of active oxygens and dissipation of excess photons. Annu Rev Plant Physiol Plant Mol Biol 50: 601-639

Barkley NA, Roose ML, Krueger RR, Federici CT (2006) Assessing genetic diversity and population structure in a citrus germplasm collection utilizing simple sequence repeat markers (SSRs). Theor Appl Genet 112: $1519-1531$

Barrett HC, Rhodes AM (1976) A numerical taxonomic study of affinity relationships in cultivated Citrus and its close relatives. Syst Bot 1: 105-136

Bonnecarrere V, Borsani O, Diaz P, Capdevielle F, Blanco P, Monza J (2011) Response to photoxidative stress induced by cold in japonica rice is genotype dependent. Plant Sci 180: 726-732 
Bradford MM (1976) A rapid and sensitive method for the quantitation of microgram quantities of protein utilizing the principle of protein-dye binding. Anal Biochem 72: 248-254

Brumos J, Colmenero-Flores JM, Conesa A, Izquierdo P, Sanchez G, Iglesias DJ, Lopez-Climent MF, GomezCadenas A, Talon M (2009) Membrane transporters and carbon metabolism implicated in chloride homeostasis differentiate salt stress responses in tolerant and sensitive Citrus rootstocks. Funct Integr Genomics 9: 293-309

de Campos MKF, de Carvalho K, de Souza FS, Marur CJ, Pereira LFP, Bespalhok JC, Vieira LGE (2011) Drought tolerance and antioxidant enzymatic activity in transgenic 'Swingle' citrumelo plants overaccumulating proline. Environ Exp Bot 72: 242-250

Drew DP, Lunde C, Lahnstein J, Fincher GB (2007) Heterologous expression of cDNAs encoding monodehydroascorbate reductases from the moss, Physcomitrella patens and characterization of the expressed enzymes. Planta 225: 945-954

Fanciullino AL, Dhuique-Mayer C, Luro F, Casanova J, Morillon R, Ollitrault P (2006) Carotenoid diversity in cultivated citrus is highly influenced by genetic factors. J Agric Food Chem 54: 4397-4406

Federici CT, Fang DQ, Scora RW, Roose ML (1998) Phylogenetic relationships within the genus Citrus (Rutaceae) and related genera as revealed by RFLP and RAPD analysis. Theor Appl Genet 96: 812-822

Foyer CH, Lelandais M, Kunert KJ (1994) Photooxidative stress in plants. Physiol Plant 92: 696-717

Foyer CH, Noctor G (2000) Oxygen processing in photosynthesis: regulation and signalling. New Phytol 146: 359-388

Foyer CH, Noctor G (2003) Redox sensing and signalling associated with reactive oxygen in chloroplasts, peroxisomes and mitochondria. Physiol Plant 119: 355-364

Garcia-Lor A, Luro F, Navarro L, Ollitrault P (2012) Comparative use of InDel and SSR markers in deciphering the interspecific structure of cultivated citrus genetic diversity: a perspective for genetic association studies. Mol Genet Genomics 287: 77-94

Gill SS, Tuteja N (2010) Reactive oxygen species and antioxidant machinery in abiotic stress tolerance in crop plants. Plant Physiol Biochem 48: 909-930

Gillespie KM, Ainsworth EA (2007) Measurement of reduced, oxidized and total ascorbate content in plants. Nat Prot 2: 871-874

Gmitter FG, Jr., Hu XL (1990) The possible role of Yunnan, China, in the origin of contemporary Citrus species (Rutaceae). Econ Bot 44: 267-277

Grover A, Sabat SC, Mohanty P (1986) Effect of temperature on photosynthetic activities of senescing detached wheat leaves. Plant Cell Physiol 27: 117-126

Guy C (1999) Molecular responses of plants to cold shock and cold acclimation. J Mol Microbiol Biotechnol 1: 231-242

Guy CL (1990) Cold-acclimation and freezing stress tolerance: role of protein metabolism. Annu Rev Plant Physiol Plant Mol Biol 41: 187-223

Hertwig B, Streb P, Feierabend J (1992) Light dependence of catalase synthesis and degradation in leaves and the influence of interfering stress conditions. Plant Physiol 100: 1547-1553

Hodges DM, DeLong JM, Forney CF, Prange RK (1999) Improving the thiobarbituric acid-reactive-substances assay for estimating lipid peroxidation in plant tissues containing anthocyanin and other interfering compounds. Planta 207: 604-611

Holaday AS, Martindale W, Alred R, Brooks AL, Leegood RC (1992) Changes in activities of enzymes of carbon metabolism in leaves during exposure of plants to low-temperature. Plant Physiol 98: 1105-1114

Hossain Z, Lopez-Climent MF, Arbona V, Perez-Clemente RM, Gomez-Cadenas A (2009) Modulation of the antioxidant system in citrus under waterlogging and subsequent drainage. J Plant Physiol 166: 1391 1404

Jifon JL, Syvertsen JP (2003) Moderate shade can increase net gas exchange and reduce photoinhibition in citrus leaves. Tree Physiol 23: 119-127

Krause GH, Briantais JM, Vernotte C (1983) Characterization of chlorophyll fluorescence quenching in chloroplasts by fluorescence spectroscopy at 77-K.1. delta-pH-dependent quenching. Biochim Biophys Acta 723: 169-175

Lim CS, Kang SM, Cho JL, Gross KC (2009) Antioxidizing enzyme activities in chilling-sensitive and chillingtolerant pepper fruit as affected by stage of ripeness and storage temperature. J Am Soc Hortic Sci 134: 156-163

Mabberley DJ (2004) Citrus (Rutaceae): A review of recent advances in etymology, systematics and medical applications. Blumea 49: 481-498

Mai J, Herbette S, Vandame M, Cavaloc E, Julien JL, Ameglio T, Roeckel-Drevet P (2010) Contrasting strategies to cope with chilling stress among clones of a tropical tree, Hevea brasiliensis. Tree Physiol 30: 1391-1402

Maxwell K, Johnson GN (2000) Chlorophyll fluorescence - a practical guide. J Exp Bot 51: 659-668 
Medina CL, Souza RP, Machado EC, Ribeiro RV, Silva JAB (2002) Photosynthetic response of citrus grown under reflective aluminized polypropylene shading nets. Sci Hortic 96: 115-125

Mittler R (2002) Oxidative stress, antioxidants and stress tolerance. Trends Plant Sci 7: 405-410

Monteith JL (1965) Evaporation and environment. Symp Soc Exp Biol 19: 205-234

Moore GA, Tozlu I, Champ K, Weber CA, Guy CL (2000) Molecular genetic studies on cold acclimation and freezing tolerance in citrus. Proceedings of the international society of citriculture, Orlando, Florida, USA, pp 405-409

Nicolosi E, Deng ZN, Gentile A, La Malfa S, Continella G, Tribulato E (2000) Citrus phylogeny and genetic origin of important species as investigated by molecular markers. Theor Appl Genet 100: 1155-1166

Noctor G, Foyer CH (1998) Ascorbate and glutathione: Keeping active oxygen under control. Annu Rev Plant Physiol Plant Mol Biol 49: 249-279

Oberley LW, Spitz DR (1984) Assay of superoxide dismutase activity in tumor-tissue. Methods Enzymol 105: 457-464

Oquist G, Huner NPA (2003) Photosynthesis of overwintering evergreen plants. Annu Rev Plant Biol 54: 329355

Palatnik JF, Valle EM, Federico ML, Gomez LD, Melchiorre MN, Paleo AD, Carrillo N, Acevedo A (2002) Status of antioxidant metabolites and enzymes in a catalase-deficient mutant of barley (Hordeum vulgare L.). Plant Sci 162: 363-371

Polle A, Rennenberg H (1992) Field studies on norway spruce trees at high-altitudes.2.defense systems against oxidative stress in needles. New Phytol 121: 635-642

Queval G, Issakidis-Bourguet E, Hoeberichts FA, Vandorpe M, Gakiere B, Vanacker H, Miginiac-Maslow M, Van Breusegem F, Noctor G (2007) Conditional oxidative stress responses in the Arabidopsis photorespiratory mutant cat2 demonstrate that redox state is a key modulator of daylength-dependent gene expression, and define photoperiod as a crucial factor in the regulation of $\mathrm{H} 2 \mathrm{O} 2$-induced cell death. Plant J 52: 640-657

Rahman I, Kode A, Biswas SK (2006) Assay for quantitative determination of glutathione and glutathione disulfide levels using enzymatic recycling method. Nat Prot 1:3159-3165

Ribeiro RV, Machado EC (2007) Some aspects of citrus ecophysiology in subtropical climates: re-visiting photosynthesis under natural conditions. Braz J Plant Physiol 19: 393-411

Ribeiro RV, Machado EC, Santos MG, Oliveira RF (2009) Seasonal and diurnal changes in photosynthetic limitation of young sweet orange trees. Environ Exp Bot 66: 203-211

Santos C, Ribeiro R, Magalhes JR, Machado D, Machado E (2011) Low substrate temperature imposes higher limitation to photosynthesis of orange plants as compared to atmospheric chilling. Photosynthetica 49: 546-554

Scora RW (1975) Symposium on biochemical systematics, genetics and origin of cultivated plants .9. history and origin of citrus. Bull Torrey Bot Club 102: 369-375

Sevillano L, Sanchez-Ballesta MT, Romojaro F, Flores FB (2009) Physiological, hormonal and molecular mechanisms regulating chilling injury in horticultural species. Postharvest technologies applied to reduce its impact. J Sci Food Agric 89: 555-573

Shang W, Feierabend J (1999) Dependence of catalase photoinactivation in rye leaves on light intensity and quality and characterization of a chloroplast-mediated inactivation in red light. Photosynth Res 59: 201 213

Smith IK, Vierheller TL, Thorne CA (1988) Assay of glutathione-reductase in crude tissue-homogenates using 5,5'-dithiobis(2-nitrobenzoic acid). Anal Biochem 175: 408-413

Stevens R, Page D, Gouble B, Garchery C, Zamir D, Causse M (2008) Tomato fruit ascorbic acid content is linked with monodehydroascorbate reductase activity and tolerance to chilling stress. Plant Cell Environ. 31: 1086-1096

Swingle WT, Reece PC (1967) The botany of Citrus and orange relatives in the orange subfamily. In: Reuther W, Webber HJ, Batchelor DL (eds) Citrus Industry, vol 1. California University Press, Berkeley, pp 190340

Verhoeven AS, Swanberg A, Thao M, Whiteman J (2005) Seasonal changes in leaf antioxidant systems and xanthophyll cycle characteristics in Taxus x media growing in sun and shade environments. Physiol Plant 123: 428-434

Veste M, Ben-Gal A, Shani U (2000) Impact of thermal stress and high VPD on gas exchange and chlorophyll fluorescence of Citrus grandis under desert conditions. Acta Hort.: 143-149

Wang X, Peng Y, Singer JW, Fessehaie A, Krebs SI, Arora R (2009) Seasonal changes in photosynthesis, antioxidant systems and ELIP expression in a thermonastic and non-thermonastic Rhododendron species: A comparison of photoprotective strategies in overwintering plants. Plant Sci 177: 607-617 
Webber HJ, Reuther W, Lawton HW (1967) History and development of the citrus industry. In: Reuther W, Webber H, Batchelor L (eds) The Citrus Industry, vol 1. Division of Agricultural Sciences, University of California, Riverside, pp 1-39

Yang GH, Yang LT, Jiang HX, Li Y, Wang P, Chen LS (2012) Physiological impacts of magnesium-deficiency in Citrus seedlings: photosynthesis, antioxidant system and carbohydrates. Trees. doi:10.1007/s00468012-0699-2

Yelenosky G (1985) Cold hardiness in Citrus. Hortic Rev 7: 201-238

Yelenosky G, Guy CL (1989) Freezing tolerance of citrus, spinach, and petunia leaf tissue - osmotic adjustment and sensitivity to freeze induced cellular dehydration. Plant Physiol 89: 444-451

Zhou B, Wang J, Guo Z, Tan H, Zhu X (2006) A simple colorimetric method for determination of hydrogen peroxide in plant tissues. Plant Growth Regul 49: 113-118 
Table 1 Genotypes used for physiological and biochemical analysis and their corresponding rootstocks

\begin{tabular}{|c|c|c|c|c|c|c|}
\hline \multicolumn{4}{|c|}{ Genotype } & \multicolumn{3}{|c|}{ Corresponding rootstock } \\
\hline Abbreviation & Common name & Tanaka system & $\mathrm{ICVN}^{\mathrm{a}}$ No. & Common name & Tanaka system & ICVN $^{\mathrm{a}}$ No. \\
\hline $\mathrm{CC}$ & Corsican citron & Citrus medica L. & 0100613 & Volkamer lemon & Citrus limonia Osbeck & 0100729 \\
\hline WLM & Willowleaf mandarin & Citrus deliciosa Ten. & 0100133 & Volkamer lemon & Citrus limonia Osbeck & 0100729 \\
\hline MK & Marumi kumquat & Fortunella japonica (Thunb.) Swingle & 0100482 & Volkamer lemon & Citrus limonia Osbeck & 0100729 \\
\hline PP & Pink pummelo & Citrus maxima (Burm.) Merr. & 0100322 & Trifoliate orange & Poncirus trifoliata (L.) Raf. & 0110480 \\
\hline
\end{tabular}

${ }^{\mathrm{a}}$ International citrus variety numbering. 
Table 2 Probabilities produced by analysis of variance (ANOVA) on data sets of orchard conditions

\begin{tabular}{|c|c|c|c|c|c|c|c|c|c|c|c|c|c|c|c|c|}
\hline & Pnet & $P \max$ & $G \mathrm{~s}$ & $\mathrm{Fv} / \mathrm{Fm}$ & $\mathrm{H}_{2} \mathrm{O}_{2}$ & MDA & tAsa & Asa & DHA & Asa/DHA & tGsh & Gsh & GssG & Gsh/GssG & SOD & CAT \\
\hline A (genotype) & $10^{-15}$ & $10^{-16}$ & $10^{-8}$ & $10^{-16}$ & $10^{-13}$ & $10^{-14}$ & $10^{-16}$ & $10^{-11}$ & $10^{-16}$ & $10^{-5}$ & $10^{-14}$ & $10^{-9}$ & $10^{-12}$ & 0.017 & $10^{-9}$ & $10^{-13}$ \\
\hline B (season) & $10^{-15}$ & $10^{-10}$ & $10^{-15}$ & $10^{-16}$ & $10^{-6}$ & $10^{-16}$ & $10^{-6}$ & $10^{-11}$ & $10^{-13}$ & $10^{-9}$ & $10^{-16}$ & $10^{-16}$ & $10^{-9}$ & $10^{-13}$ & $10^{-6}$ & $10^{-16}$ \\
\hline $\mathrm{C}(\mathrm{A} \times \mathrm{B})$ & $10^{-11}$ & $10^{-11}$ & $10^{-5}$ & $10^{-7}$ & 0.057 & 0.0004 & 0.001 & 0.798 & $10^{-6}$ & 0.051 & $10^{-6}$ & 0.0008 & $10^{-5}$ & $10^{-5}$ & 0.291 & $10^{-15}$ \\
\hline
\end{tabular}

APX MDHAR DHAR GR

$\begin{array}{lcccc}\text { A (genotype) } & 10^{-15} & 10^{-9} & 10^{-7} & 10^{-5} \\ \text { B (season) } & 0.0002 & 10^{-7} & 10^{-12} & 10^{-5} \\ \mathrm{C}(\mathrm{A} \times \mathrm{B}) & 10^{-7} & 10^{-6} & 0.621 & 10^{-5}\end{array}$

Initial data were subjected to a two-way analysis of variance. The qualitative factors studied were genotype and season and their interaction. The analyses were performed on a group of three trees. The $P$ values showing the level of significance of each qualitative factor are presented. 
Table 3 Effects of seasonal changes on total ascorbate content (tAsa), reduced ascorbate content (Asa), oxidized ascorbate content (DHA) and redox status (Asa/DHA) in leaves of four citrus genotypes.

\begin{tabular}{|c|c|c|c|c|}
\hline Genotype & tAsa $\left(\mu \mathrm{mol} . \mathrm{g}^{-1} \mathrm{FW}\right)$ & Asa $\left(\mu\right.$ mol. $\left.\mathrm{g}^{-1} \mathrm{FW}\right)$ & DHA $\left(\mu\right.$ mol.g $\left.{ }^{-1} \mathrm{FW}\right)$ & Asa/DHA \\
\hline \multicolumn{5}{|l|}{$\mathrm{CC}$} \\
\hline WP & $23.64 \pm 1.24^{\mathrm{d}}$ & $12.67 \pm 1.00^{\mathrm{f}}$ & $10.97 \pm 0.33^{\mathbf{b}}$ & $1.15 \pm 0.07^{\mathrm{d}}$ \\
\hline $\mathrm{CP}$ & $37.22 \pm 0.55^{\text {ab }}$ & $16.68 \pm 0.46^{\mathrm{de}}$ & $20.53 \pm 0.84^{\mathrm{a}}$ & $0.82 \pm 0.05^{\mathrm{e}}$ \\
\hline \multicolumn{5}{|l|}{ MK } \\
\hline WP & $22.69 \pm 0.51^{\mathrm{d}}$ & $15.74 \pm 1.00^{\mathrm{e}}$ & $6.94 \pm 0.75^{\mathrm{c}}$ & $2.46 \pm 0.48^{b}$ \\
\hline $\mathrm{CP}$ & $40.40 \pm 1.25^{\mathrm{a}}$ & $20.67 \pm 0.73^{\mathbf{b}}$ & $19.72 \pm 0.98^{\mathrm{a}}$ & $1.06 \pm 0.06^{\mathrm{d}}$ \\
\hline \multicolumn{5}{|l|}{ WLM } \\
\hline WP & $25.25 \pm 1.24^{\mathrm{d}}$ & $19.13 \pm 0.77^{\text {bc }}$ & $6.11 \pm 0.68^{\mathrm{c}}$ & $3.27 \pm 0.30^{\mathrm{a}}$ \\
\hline $\mathrm{CP}$ & $35.06 \pm 1.44^{\mathbf{b}}$ & $24.47 \pm 0.94^{\mathrm{a}}$ & $10.59 \pm 0.93^{\mathbf{b}}$ & $2.39 \pm 0.21^{\mathbf{b}}$ \\
\hline \multicolumn{5}{|l|}{$\mathrm{PP}$} \\
\hline WP & $20.22 \pm 0.33^{\mathrm{e}}$ & $13.30 \pm 0.48^{\mathrm{f}}$ & $6.91 \pm 0.20^{\mathrm{c}}$ & $1.93 \pm 0.11^{\mathrm{b}}$ \\
\hline $\mathrm{CP}$ & $30.57 \pm 0.77^{\mathrm{c}}$ & $18.55 \pm 0.29^{\mathrm{cd}}$ & $12.02 \pm 0.68^{b}$ & $1.57 \pm 0.10^{\mathbf{c}}$ \\
\hline
\end{tabular}

The data are presented as mean values \pm standard errors of six independent replicated samples $(n=6)$. In the same column, statistically significant differences among genotypes at $P<0.05$ for Fisher's LSD pairwise comparisons are indicated for each mean value in the warm period (WP) and the cold period (CP) by different letters. 
Table 4 Effects of seasonal changes on total glutathione content (tGsh), reduced glutathione content (Gsh), oxidized glutathione content (GssG) and redox status (Gsh/GssG) in leaves of four citrus genotypes.

\begin{tabular}{ccccc}
\hline Genotype & tGsh $\left(\mathrm{nmol} . \mathrm{g}^{-1} \mathrm{FW}\right)$ & Gsh $\left(\mathrm{nmol} . \mathrm{g}^{-1} \mathrm{FW}\right)$ & GssG $\left(\mathrm{nmol} . \mathrm{g}^{-1} \mathrm{FW}\right)$ & Gsh/GssG \\
\hline CC & & & & \\
WP & $751.02 \pm 41.04^{\mathbf{b}}$ & $634.62 \pm 31.35^{\mathbf{b}}$ & $116.39 \pm 11.65^{\mathbf{c}}$ & $5.64 \pm 0.41^{\mathbf{a}}$ \\
CP & $1279.13 \pm 70.87^{\mathbf{a}}$ & $978.36 \pm 77.97^{\mathbf{a}}$ & $300.77 \pm 21.66^{\mathbf{a}}$ & $3.39 \pm 0.47^{\mathbf{b}}$ \\
MK & & & \\
WP & $198.68 \pm 10.02^{\mathrm{e}}$ & $94.67 \pm 3.92^{\mathbf{f}}$ & $104.01 \pm 7.36^{\mathbf{c}}$ & $0.92 \pm 0.05^{\mathbf{e}}$ \\
CP & $701.61 \pm 67.87^{\mathbf{b}}$ & $420.31 \pm 49.83^{\mathbf{c}}$ & $281.29 \pm 37.11^{\mathbf{a}}$ & $1.59 \pm 0.20^{\mathbf{d}}$ \\
WLM & & & & \\
WP & $160.73 \pm 13.73^{\mathbf{e}}$ & $99.58 \pm 10.64^{\mathbf{f}}$ & $61.15 \pm 6.53^{\mathbf{d}}$ & $1.71 \pm 0.22^{\mathbf{d}}$ \\
CP & $270.97 \pm 13.59^{\mathbf{d}}$ & $163.13 \pm 15.61^{\mathbf{e}}$ & $107.84 \pm 5.15^{\mathbf{c}}$ & $1.54 \pm 0.20^{\mathbf{d}}$ \\
PP & & & $102.81 \pm 9.23^{\mathbf{c}}$ & \\
WP & $333.7 \pm 26.88^{\mathbf{d}}$ & $230.88 \pm 22.69^{\mathbf{d}}$ & $159.29 \pm 7.21^{\mathbf{b}}$ & $2.30 \pm 0.25^{\mathbf{c}}$ \\
CP & $525.82 \pm 22.21^{\mathbf{c}}$ & $366.53 \pm 21.09^{\mathbf{c}}$ & & \\
& & & & \\
\hline
\end{tabular}

The data are presented as mean values \pm standard errors of six independent replicated samples $(n=6)$. In the same column, statistically significant differences among genotypes at $P<0.05$ for Fisher's LSD pairwise comparisons are indicated for each mean value in the warm period (WP) and the cold period (CP) by different letters. 


\section{Figure captions}

Fig. 1 Changes in (a) net photosynthetic rate (Pnet) and (b) stomatal conductance $(G s)$ in four citrus genotypes in the warm period (black bars) and cold period (white bars). All data are presented as mean values $( \pm$ S.E.) of nine independent measurements $(n=9)$. Bars followed by different letters indicate statistically significant differences at $P<0.05$ for Fisher's LSD pairwise comparisons

Fig. 2 Comparison of net photosynthetic rate (Pnet) of four citrus genotypes under orchard climatic conditions (white bars) and growth chamber conditions (black bars). Pnet was measured under (a) September orchard conditions and on detached leaves at $25{ }^{\circ} \mathrm{C}$ or (b) under January orchard conditions and on detached leaves at $6{ }^{\circ} \mathrm{C}$. The data are presented as mean values ( \pm S.E.) of 6-9 independent measurements. Bars followed by different letters indicate statistically significant differences at $P<0.05$ for Fisher's LSD pairwise comparisons

Fig. 3 Changes of (a) maximal quantum yield of photosystem II $(F \mathrm{v} / F \mathrm{~m})$ and (b) maximum photosynthetic rate (Pmax) in four citrus genotypes in the warm period (black bars) and cold period (white bars). All data are presented as mean values $( \pm$ S.E. $)$ of nine independent measurements $(n=9)$. Bars followed by different letters indicate statistically significant differences at $P<0.05$ for Fisher's LSD pairwise comparisons

Fig. 4 Changes in (a) hydrogen peroxide $\left(\mathrm{H}_{2} \mathrm{O}_{2}\right)$ and (b) malondialdehyde (MDA) content in four citrus genotypes in the warm period (black bars) and cold period (white bars). All data are presented as mean values $( \pm$ S.E. $)$ of six independent measurements $(n=6)$. Bars followed by different letters indicate statistically significant differences at $P<0.05$ for Fisher's LSD pairwise comparisons

Fig. 5 Changes in the specific activities of (a) superoxide dismutase (SOD), (b) catalase (CAT) and (c) ascorbate peroxidase (APX) in four citrus genotypes in the warm period (black bars) and cold period (white bars). All data are presented as mean values $( \pm$ S.E.) of six independent measurements $(n=6)$. Bars followed by different letters indicate statistically significant differences at $P<0.05$ for Fisher's LSD pairwise comparisons

Fig. 6 Changes in the specific activities of (a) monodehydroascorbate reductase (MDHAR), (b) dehydroascorbate reductase (DHAR) and (c) glutathione reductase (GR) in four citrus genotypes in the warm period (black bars) and cold period (white bars). All data are presented as mean values $( \pm$ S.E.) of six independent measurements $(n=6)$. Bars followed by different letters indicate statistically significant differences at $P<0.05$ for Fisher's LSD pairwise comparisons 
Figure 1

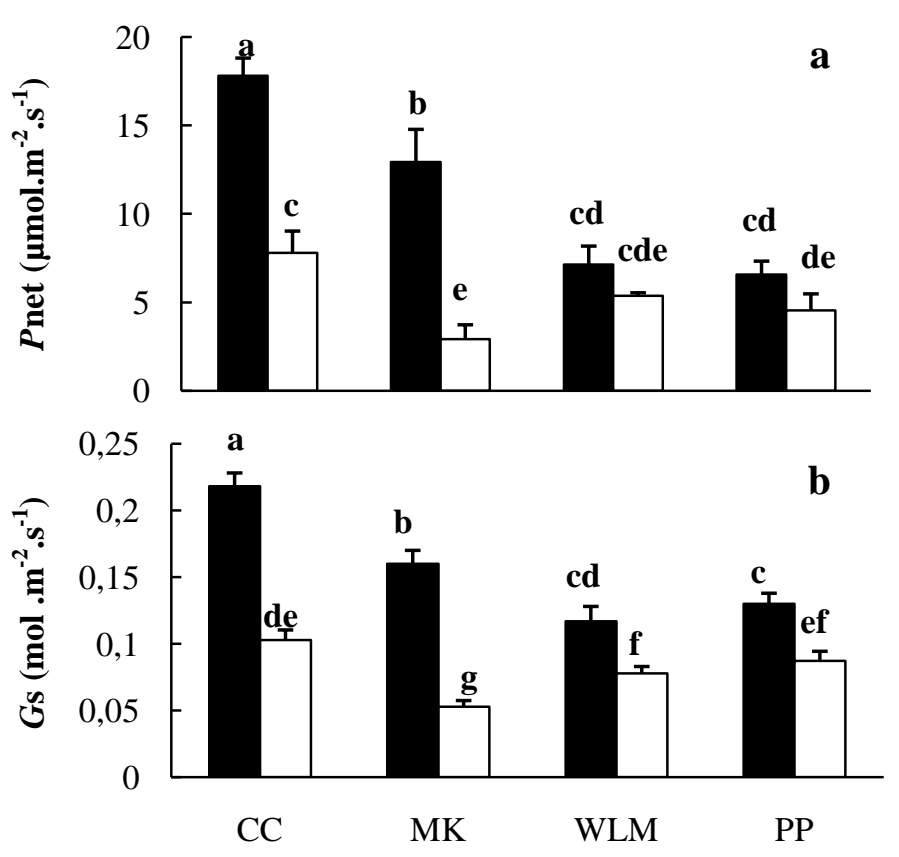




$$
\text { IIon }
$$


Figure 3

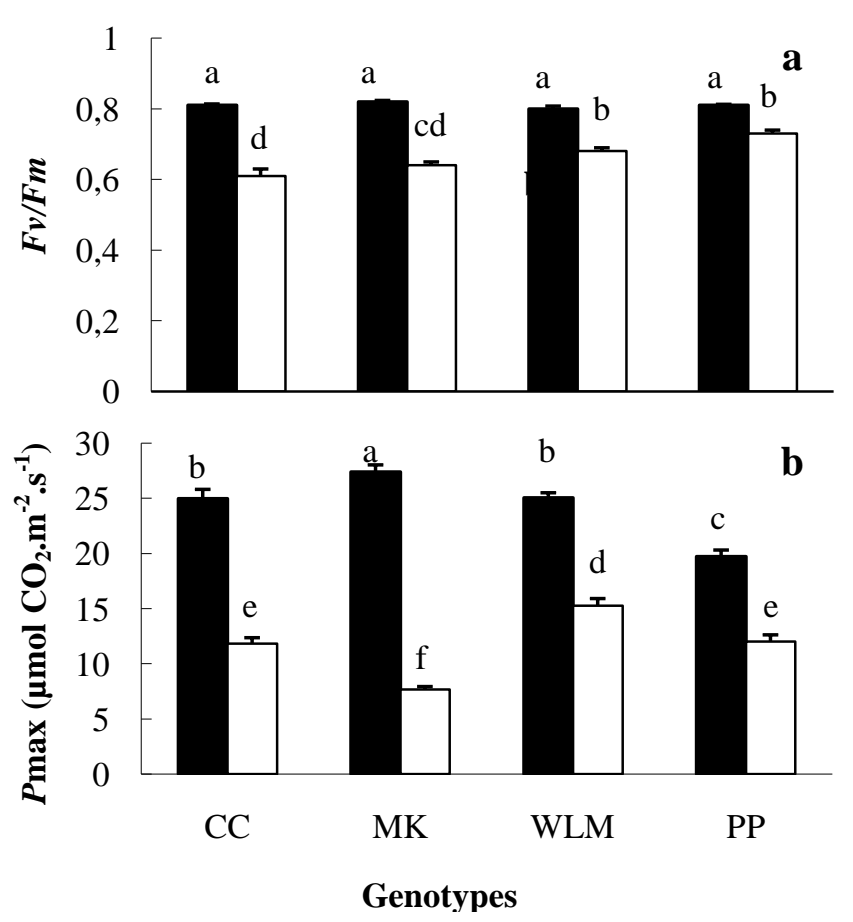


Figure 4

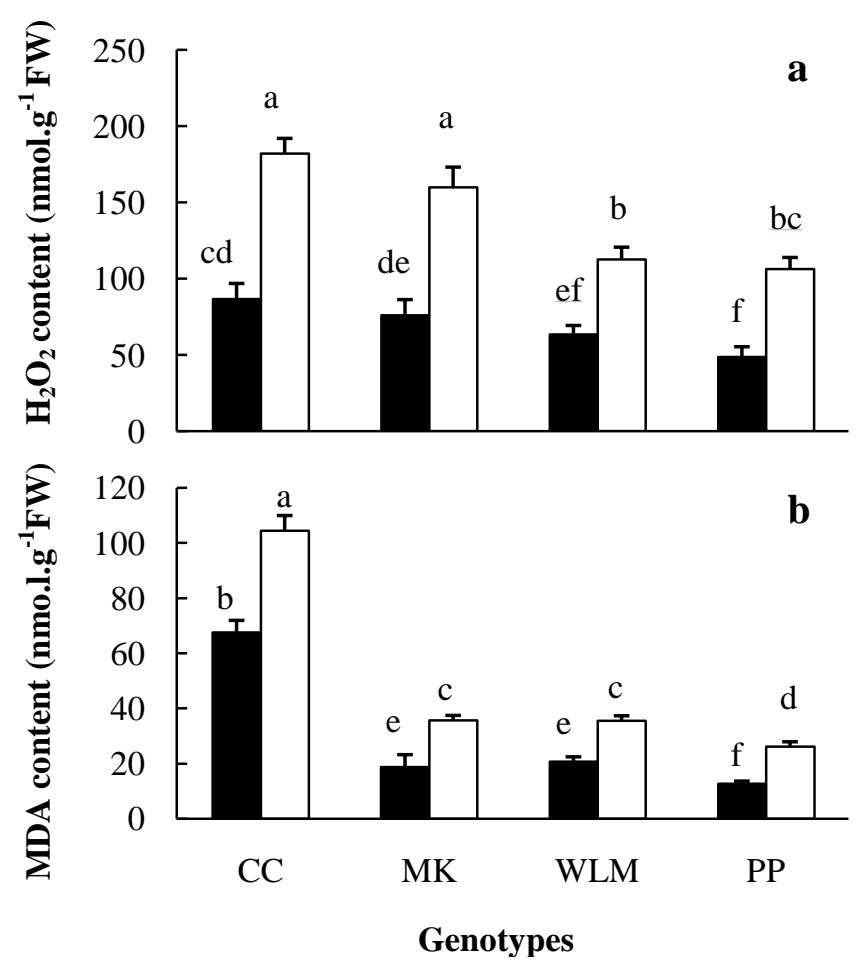


Figure 5
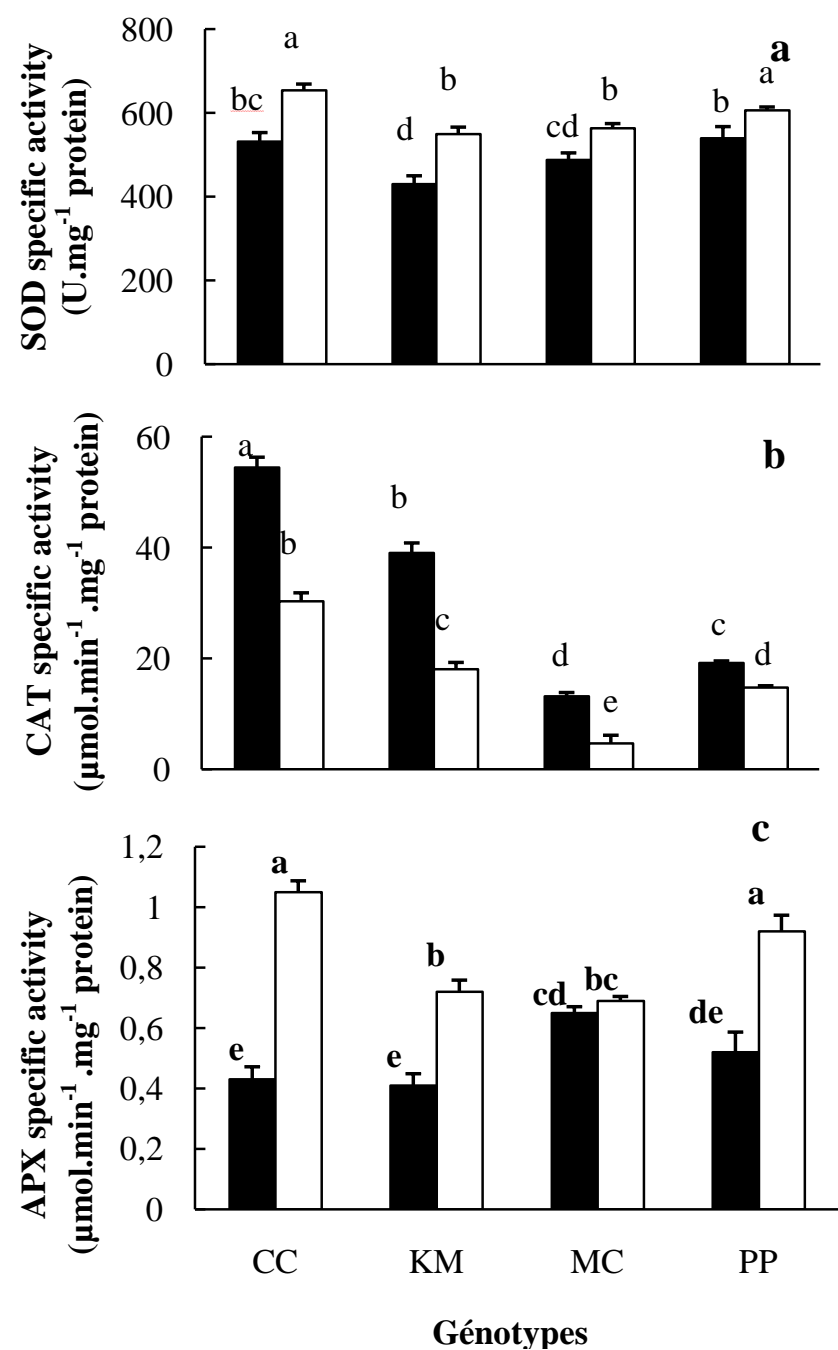
Figure 6
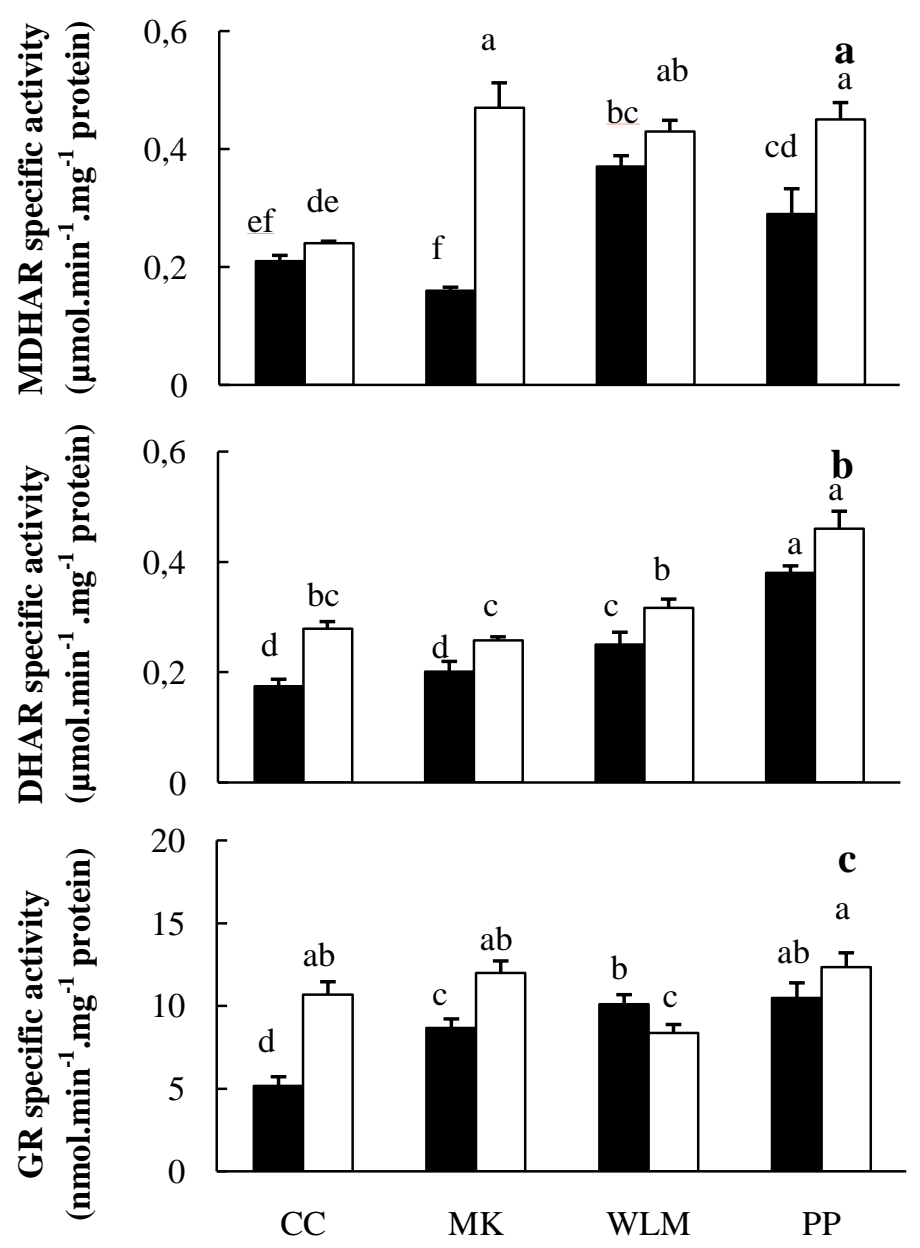

Genotypes 